\title{
Severe local skin reaction after the application of ingenol mebutate gel treated by photodynamic therapy: A case report
}

\author{
Luca Negosanti ${ }^{1 *}$, Rossella Sgarzani ${ }^{1}$, Matteo Santoli ${ }^{2}$, Massimino Negosanti ${ }^{3}$, \\ Nicoletta Banzola ${ }^{3}$, Francesca Negosanti ${ }^{4}$ \\ ${ }^{1}$ Division of Plastic Surgery, S.Orsola-Malpighi University Hospital, Bologna, Italy \\ ${ }^{2}$ Division of Plastic Surgery, Bellaria Hospital, Bologna, Italy \\ ${ }^{3}$ Division of Dermatology, S.Orsola-Malpighi University Hospital, Bologna, Italy \\ ${ }^{4}$ Division of Dermatology, Centro Dermatologico Srl, Bologna, Italy
}

\begin{abstract}
Ingenol mebutate (IM) was recently introduced for the treatment of actinic keratosis (AK). It is considered a safe and effective treatment in spite of local reactions frequently reported. These reactions may consist of erythema, flaking, crusting, swelling, vesicles and erosions, and would usually spontaneously recede within 20-30 days. We reported a case of a patient affected by multiple actinic keratosis of the scalp treated with IM. The patient reported a severe reaction that was not solved in two months. We decided to treat the reaction with photodynamic therapy and aminolevulinic acid. This treatment was demonstrated to be effective in solving this severe side effect.

Keywords: actinic keratosis; ingenol mebutate; photodynamic therapy

Citation: Negosanti L, Sgarzani R, Santoli M, Negosanti M, Banzola N, et al. Severe local skin reaction after the application of Ingenol Mebutate gel treated by photodynamic therapy: A case report. J Surg Dermatol 2018; 3(1): 36; http://dx.doi.org/10.18282/jsd.v1.i1.36.
\end{abstract}

*Correspondence to: Luca Negosanti, Centro Dermatologico Srl, Via Mazzini 2/2, 40138, Bologna, Italy; luca.negosanti81@gmail. com

Received: $2^{\text {nd }}$ August 2017; Accepted: $4^{\text {th }}$ October 2017; Published Online: $17^{\text {th }}$ October 2017

\section{Introduction}

Ingenol mebutate (IM) was recently introduced for the treatment of actinic keratosis (AK). It consists of self-administered therapy by applying IM on the affected skin surface with multiple AK for two consecutive days (trunk and extremities) or three days (scalp and face). It is considered a safe and effective treatment in spite of local reactions frequently reported ${ }^{[1]}$. These reactions may consist of erythema, flaking, crusting, swelling, vesicles and erosions, and would usually spontaneously recede within 20-30 days ${ }^{[2]}$.

In our experience, we observed a severe local reaction that did not demonstrate any signs of healing after 50 days of treatment. This reaction was successfully treated using photodynamic therapy (PDT) with aminolevulinic $\operatorname{acid}(\mathrm{ALA})^{[3]}$.

\section{Case report}

A 62-year-old male patient presented with multiple AK of the scalp (Figure 1). We decided to apply $150 \mu \mathrm{g} / \mathrm{g}$ of IM for three consecutive days on a surface area of 25 $\mathrm{cm}^{2}$ in order to treat the entire surface in a single stage. The patient was adequately informed about the nature of treatment, the possible side effects and the expected results. A control was planned one week after the first day of therapy. Local application of antibiotic and steroids (Gentamicin and Betamethasone) was prescribed for 10 days.

Copyright $\odot 2018$ Negosanti L et al. This is an Open Access article distributed under the terms of the Creative Commons Attribution-Non Commercial 4.0 International License (http://creativecommons.org/licenses/by-nc/4.0/), permitting all non-commercial use, distribution, and reproduction in any medium, provided the original work is properly cited. 


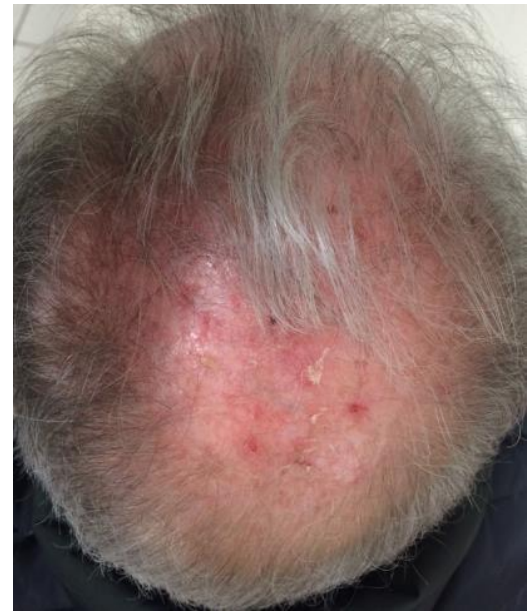

Figure 1. Patient presented with multiple AK of the scalp

After 7 days, the patient presented a local reaction characterized by multiple crusts with modest swelling. We previously observed this reaction in other patients, so we decided to continue the local therapy and planned controls every week.

The reaction increased in intensity progressively and presented no signs of resolution. After two months the patient presented severe crust reaction all over the scalp (Figure 2). We decided to perform a surgical toilet of the crust and observed the severe swelling underneath it. The skin presented an intense inflammatory reaction and granulation tissue. No biopsy was performed. In order to solve this situation, we applied ALA $20 \%$ all over the scalp and after two hours, PDT was administered for 12 min. PDT was set with a wavelength of $633+6 \mathrm{~nm}$, an intensity of $105 \mathrm{~mW} / \mathrm{cm}^{2}$ and a dose of $126 \mathrm{~J} / \mathrm{cm}^{2} .30$

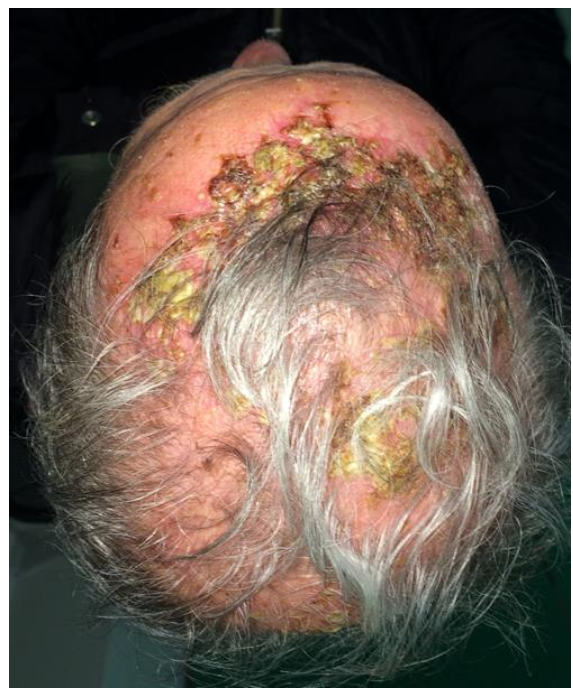

Figure 2. A local reaction at two months after IM application days after the first session, we observed complete resolution of the inflammatory reaction with some residual AK. The reaction receded progressively and the PDT treatment was therefore repeated one month after the previous session. 30 days after the second session, we obobserved low signs of inflammation and no residual AK (Figure 3).

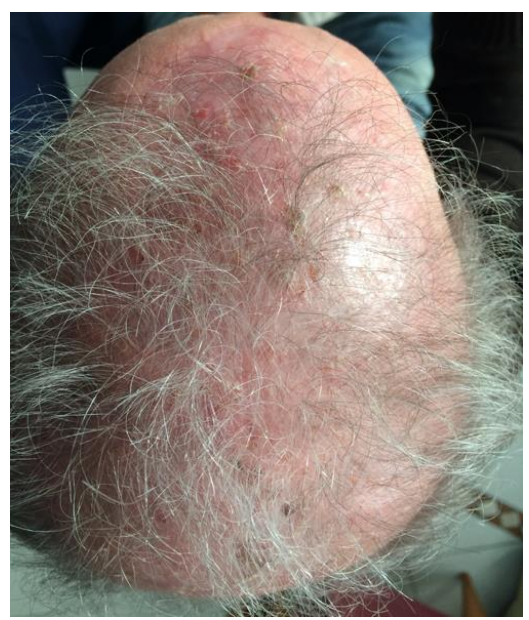

Figure 3. Results 30 days after the first treatment session of ALA-PDT

\section{Conclusion}

IM is recently introduced as therapy for AK. Over the past few years, we treated 36 patients affected by multiple AK with IM. Our population consisted of 28 males and 8 females with a mean age of 69 years old (range 61-77). The interested treatment sites were trunk and extremities in 24 cases, and face and scalp in 12 cases. We applied IM $500 \mu \mathrm{g} / \mathrm{g}$ for two consecutive days on a surface area of $25 \mathrm{~cm}^{2}$ on trunk or extremities and IM $150 \mu \mathrm{g} / \mathrm{g}$ for three consecutive days on a surface area of $25 \mathrm{~cm}^{2}$ on the face and scalp. We observed the reported local reactions with complete healing in a mean time of 27 days (range 18-36). In just one case, we observed a severe local reaction that did not demonstrate any signs of healing after 50 days of treatment. This reaction was successfully treated using PDT with $\mathrm{ALA}^{[3]}$. This type of treatment association was described by Berman et al., but not for the treatment of severe local reaction after IM application ${ }^{[4]}$.

In the presented case, we observed a severe local reaction characterized by inflammation, swelling and crusts all over the treated area that did not recede within 60 days. The clinical aspect of the reaction was similar to a hypertrophic AK associated with an infective affection. Considering the well-known utility of ALA-PDT in the 
treatment of both AK and infective diseases, we applied it on the patient's skin in order to solve the severe local reaction ${ }^{[5]}$. We observed a complete resolution just after two sessions of PDT. Such intense and lasting reaction after IM application has never been reported in any literature. ALA-PDT was demonstrated to be effective in solving this severe side effect. The main reason can be linked to the efficacy of ALA-PDT both on neoplastic and infective diseases of the skin.

\section{Conflict of interest}

The authors declared no potential conflict of interest with respect to the research, authorship, and/or publication of this article.

\section{References}

1. Lebwohl M, Swanson N, Anderson LL, Melgaard A, Xu Z, et al. Ingenol mebutate gel for actinic keratosis. N Engl J Med 2012; 366: 1010-1019. doi: 10.1056/NEJMoa1111170.
2. Longo C, Neri L, Argenziano G, Calvieri S, CalzavaraPinton PG, et al. Management of local skin reactions after the application of ingenol mebutate gel for the treatment of actinic keratosis: Four illustrative cases. J Eur Acad Dermatol Venereol 2014; 30(2): 320-321. doi:10.1111/jdv. 12714 .

3. Negosanti L, Pinto V, Sgarzani R, Negosanti F, Zannetti G, et al. Photodynamic therapy with topical aminolevulinic acid. World J Dermatol 2014; 3(2): 6-14. doi: 10.5314/ wjd.v3.i2.6.

4. Berman B, Nestor MS, Newburger J, Park H, Swenson N. Treatment of facial actinic keratoses with aminolevulinic acid photodynamic therapy (ALA-PDT) or ingenol mebutate $0.015 \%$ gel with and without prior treatment with ALA-PDT. J Drugs Dermatol 2014; 13(11): 1353-1356.

5. Pariser DM, Eichenfield LF, Bukhalo M, Waterman G, Jarratt M, et al. Photodynamic therapy with $80 \mathrm{mg} / \mathrm{g}$ methyl aminolaevulinate for severe facial acne vulgaris: A randomised vehicle-controlled study. Br J Dermatol 2015. doi: $10.1111 /$ bjd.14345. 